\title{
AVALIAÇÃO INSTITUCIONAL NA UNIVERSIDADE AGOSTINHO NETO (ANGOLA) E REGULAÇÃO ESTATAL. PERSPECTIVAS, PRÁTICAS E DESAFIOS
}

\author{
EugÉnio Alves Da Silva* \\ Maria da Conceição Barbosa Mendes**
}

Recebido: 17 fev. 2011

Aprovado: 08 maio 2012

\begin{abstract}
* Doutor. Docente no Instituto de Educação da Universidade do Minho. Investigador no Centro de Investigação em Educação da Universidade do Minho, Campus de Gualtar. Braga, Portugal. E-mail:esilva@ ie.uminho.pt
\end{abstract}

** Mestre. Docente na Universidade Katyavala Bwila - Benguela, Angola. Investigador no Centro de Investigação em Educação da Universidade do Minho, Campus de Gualtar. Braga, Portugal. E-mail: saobarbosa67@yahoo.com.br

Resumo: A avaliação institucional nas universidades tem vindo a assumir-se em Angola como uma dimensão importante da administração e gestão universitária, enquanto mecanismo de prestação de contas e factor de regulação e desenvolvimento organizacional. Assim, os órgãos de gestão das universidades, confrontados com as exigências de qualidade e de credibilização social, sujeitam-se à avaliação institucional visando a monitorização do seu desenvolvimento e a melhoria da qualidade educativa. Com este texto pretende-se analisar e compreender a relevância, a pertinência e o lugar da avaliação institucional na Universidade Agostinho Neto, partindo da análise das justificações (argumentos, representações) de vários gestores universitários, bem como das lógicas subjacentes à política de avaliação institucional, adoptando para o efeito três perspectivas distintas de análise organizacional.

Palavras-chave: Avaliação institucional. Regulação. Prestação de contas. Qualidade educativa. Credibilidade social. Certificação.

\section{INSTITUTIONAL EVALUATION AT THE AGOSTINHO NETO UNIVERSITY (ANGOLA) AND STATE REGULATION. PERSPECTIVES, PRACTICES AND CHALLENGES.}

Abstract: Institutional evaluation in universities has been assumed in Angola as an important dimension of university administration and management, as a mechanism of accountability and as a factor of regulation and organizational development. Thus, the management structures of universities, faced with the demands of quality and social credibility, subject themselves to institutional evaluation in order to monitor its development and improve educational quality. With this paper we intend to analyze and understand the importance, relevance and place of institutional evaluation at Agostinho Neto University, analyzing the justifications (arguments, representations) of several university administrators, as well as the underlying logic of institutional evaluation policy, adopting for this purpose three different perspectives of organizational analysis.

Keywords: Institutional evaluation. Regulation. Accountability. Educational quality. Social credibility. Certification. 


\section{INTRODUÇÃO}

A reestruturação do subsistema de ensino superior em Angola e o desenvolvimento actual da Universidade Agostinho Neto (UAN) assentam na ideia da melhoria da qualidade educativa, segundo lógicas de uma melhor gestão das Instituições de Ensino Superior (IES). As "Linhas mestras para a melhoria da gestão do subsistema do ensino superior”, da Secretaria de Estado para o Ensino Superior (SEES, 2005), preconizam, por um lado, a aposta na promoção da qualidade e, por outro, a adopção de um sistema de avaliação da qualidade das IES como forma de assegurar a sua certificação junto da tutela.

À avaliação é conferida uma dimensão reguladora tendente à melhoria da qualidade educativa sobre a qual se pretende construir a credibilidade social da universidade. Assim, ela é tomada como vertente importante da administração e gestão universitárias, enquanto mecanismo de prestação de contas mas também como factor de regulação e desenvolvimento profissional e organizacional. Além disso, surge associada à certificação e acreditação das IES, num processo de recuperação do prestígio social das universidades e do ensino superior em Angola.

Ainda que não haja experiência e debate suficientes neste domínio nem interiorização e compreensão sobre a natureza, problemas, exigências e benefícios da avaliação institucional, os órgãos máximos da UAN, confrontados com as demandas de qualidade e certificação, reconhecem a inevitabilidade da implantação de um sistema de avaliação institucional para promover a pilotagem do seu desenvolvimento e a melhoria da qualidade educativa em função da qual se pretende credibilizar socialmente a universidade pública angolana.

\section{A AVALIAÇÃO INSTITUCIONAL}

Na abordagem da avaliação no ensino superior Díaz Barriga (2003, p. 8792) toma a avaliação institucional como o balanço dos rumos da instituição objectivando a qualidade e Leite (2005, p. 32) considera que "A avaliação institucional constitui um serviço prestado à sociedade à medida que os participantes da instituição possam repensar seus compromissos e metas, modos de actuação e finalidades de suas práticas e de sua missão". A credenciação institucional e de programas refere-se a "uma avaliação qualificadora, cuja finalidade é determinar quais instituições têm determinados sucessos para poder ingressar ou não num sistema de credenciamento" (DÍAZ BARRIGA, 2003, p. 89). Tal qualificação é feita segundo medidas objectivas a partir da definição de indicadores com base nos quais são determinadas as pontuações. 
Na óptica de Díaz Barriga (2003), a avaliação institucional consiste numa reflexão sobre dados relevantes, incidindo fundamentalmente sobre o processo: gestão, clareza das metas gerais e académicas, do grau de pertinência dos planos de estudos, das exigências do mercado, da actualização do conhecimento, as dinâmicas de funcionamento de um plano de estudos, seus conteúdos, seus docentes, seus estudantes, a pertinência do material bibliográfico disponível, etc. Ela visa fornecer informações pertinentes sobre a dinâmica organizacional para se identificarem as forças e fragilidades institucionais, implicando uma análise multidimensional e profunda dos diversos aspectos para produzir uma descrição e interpretação da realidade institucional.

A auto-avaliação reporta-se a processos e estratégias visando o autoconhecimento, sendo vista como uma "estrategia de revisión y mejora del desarrollo, significa que un centro genera procesos y formas de trabajo dirigidos a autorrevisar lo que se hace cotidianamente" (ZABALZA, 1987 apud ARREDONDO, 2003, p. 18). É realizada pela própria comunidade universitária, assumindo os actores um duplo estatuto: de avaliados e de avaliadores, podendo contar com assessoria de especialistas externos. Dias Sobrinho (2003, p. 46-47) lembra que a avaliação interna deve ser realizada pela comunidade universitária interna e externa, cabendo àquela a definição dos princípios, concepção básica, objectivos, objecto, sujeitos, procedimentos e usos do processo avaliativo. Deste modo, a imagem institucional é construída de dentro para fora, levando a um despertar da consciência sobre a imagem que se deseja projectar e colocar à disposição dos avaliadores externos (RISTOFF, 2003, p. 29).

Para Dias Sobrinho (2000, p. 128) a avaliação interna tem duas variantes: (i) auto-avaliação: em que os actores se vêm colocados na posição de sujeitos e parte do objecto a avaliar; (ii) heteroavaliação: os especialistas são sujeitos que têm por finalidade a ampliação de conhecimentos e, sobretudo, a valoração do objecto de análise. Por sua vez, a avaliação externa "Es la evaluación que se realiza desde fuera del ámbito escolar y que pretende ofrecer a los componentes del sistema educativo, otro punto de vista que hay que añadir a la evaluación interna que ellos realizan. Debe ser un elemento de contraste que enriquezca el proceso educativo y debe tener una dimensión propedéutica y nunca inquisitorial" (MEC, 1989 apud ARREDONDO, 2003, p. 84), o que revela o carácter público da avaliação.

A avaliação externa e interna são complementares já que, conforme explica Dias Sobrinho (2003, p.48), a instituição submete-se a uma avaliação externa após a realização da avaliação interna, cujos resultados são consolidados num relatório que serve de base para a referida avaliação externa; por outro lado, a 
avaliação externa, ao ser realizada de fora para dentro, poderá ajudar a corrigir possíveis subjectividades decorrentes da avaliação interna (erros de percepção, posicionamentos acríticos dos actores internos) do mesmo modo que "alimenta novos processos internos" (DIAS SOBRINHO, 2000, p. 127). O sentido da avaliação externa enfatiza a natureza pedagógica, pretendendo-se que tenha não um fim sancionador mas uma intenção de melhoria e desenvolvimento da instituição.

Para Broadfoot (1984) e Afonso (2005), a avaliação encarada como prestação de contas (accountability) processa-se em três níveis: micro, meso e macro. A avaliação institucional ou organizacional é enquadrada no nível meso, numa perspectiva de avaliação criterial:

baseada nos objectivos, definidos no contexto organizacional escolar, pelos órgãos de direcção que, num sistema descentralizado e mais autónomo, representam os interesses das comunidades educativas locais e que deviam estar inscritos nos respectivos projectos educativos (AFONSO, 2005, p. 36).

A avaliação educacional tem enorme importância na dinâmica das organizações porque se configura como "um instrumento fundamental em termos de gestão. Particularmente importante na estruturação das relações de trabalho [...] a avaliação é também um instrumento importante de controlo e legitimação organizacional" (AFONSO, 2003, p. 18). Sendo a universidade "uma instituição antecipatória, do tipo 'trabalho-intensiva' que pensa o hoje para construir o seu amanhã, ou seja, uma instituição permanentemente à procura do seu autoconhecimento para se reformar e se projectar no futuro" (LEITE, 2005, p. 26), a avaliação organizacional representa uma ferramenta indispensável para desencadear um processo de autoconhecimento a partir da identificação dos seus pontos frágeis e fortes, na base das quais poderá conceber planos de desenvolvimento que incluam estratégias de melhoria constante.

\section{PERSPECTIVAS DE ANÁLISE ORGANIZACIONAL DA UNIVERSIDADE}

A análise da universidade enquanto objecto de avaliação institucional implica a construção de indicadores pertinentes e representativos o que exige uma grelha conceptual de interpretação. Tendo em conta que "a escola não é simplesmente um 'dado' dado, uma realidade empírica de primeira ordem que seja passível de 'captação' imediata, sem a mediação de teorias e conceitos, implícitos ou 
explícitos" (LIMA, 2008, p. 83), convocaremos perspectivas teóricas partindo da ideia de que "toda e qualquer acção de avaliar em contexto escolar baseia-se numa concepção organizacional de escola, implícita ou explícita" (LIMA, 2002, p. 19). A construção de um marco teórico é imprescindível para compreender a avaliação no quadro das lógicas de acção pois:

Os objectivos, as modalidades e os instrumentos de avaliação adoptados, os efeitos ou consequências dos processos de avaliação, o poder de avaliar, de participar na avaliação e na interpretação dos 'resultados', entre outros elementos, diferem substancialmente consoante o protagonismo atribuído a concepções, imagens e metáforas organizacionais que, por sua vez, envolvem necessariamente opções políticas, visões do mundo e interesses traduzindo diferentes prioridades de acção (LIMA, 2002, p. 18).

Face a este quadro, a abordagem da avaliação institucional na UAN é feita segundo as perspectivas de análise burocrática, política e institucional.

\subsection{Perspectiva burocrática}

O modelo burocrático baseia-se na teoria de Weber que enfatiza os elementos formais e estruturais das organizações. Merton (1970, p. 271), referindo-se à burocracia, fala de uma estrutura social e racionalmente construída, com normas de actividades claramente definidas e cujas acções visam realizar as metas da mesma. Destaca a congruência entre os meios e os fins, entre as orientações e as acções, o que mostra o lado mais racional, rígido e previsível da estrutura. Segundo Morgan (1986, p. 27), este modelo de organização, ao privilegiar a interdependência estrutural, a alocação rígida de funções, as cadeias de comando e as linhas de autoridade, revela um funcionamento rotineiro e uma ordem conformista reforçada por mecanismos de coacção que mantêm a disciplina, a obediência e a estabilidade.

Mintzberg (1982, p. 197-226) concebe a organização burocrática como uma estrutura centralizada, hierarquizada, com um funcionamento rotineiro, uniforme e eficaz, na base de processos de coordenação e de controlo visando eliminar a incerteza e os conflitos. $\mathrm{O}$ estudo da universidade sob esta perspectiva pode levar-nos a classificá-la como burocrática, identificadas as características do modelo, que são as seguintes: (i) a legalidade, baseada na existência de normas formais que estipulam um funcionamento previsível da organização. Estas normas, de estrito cumprimento, servem para a coordenação, realização e controlo das actividades (WEBER, 1978, p. 16), estabelecendo a conformidade; (ii) a 
hierarquia, na base da qual se define uma estrutura de autoridade e controlo e uma organização de cargos, competindo a cada ocupante de um cargo o desempenho de funções segundo as atribuições e competências conferidas (WEBER, 1982, p. 16-17); (iii) a impessoalidade, caracterizada pela distribuição de tarefas de acordo com os cargos e segundo critérios definidos. Separa-se o cargo da pessoa, de tal forma que a autoridade e o poder são atributos não das pessoas mas dos cargos (WEBER, 1984, p. 26); (iv) a racionalidade, que se caracteriza pela conformidade entre os meios e os fins, de tal forma que a organização, considerada como uma estrutura composta de órgãos e papeis integrados, pode atingir eficientemente objectivos consistentes previamente definidos; (v) a especialização, que consiste em atribuir a cada membro da organização uma tarefa específica segundo critérios técnicos previamente definidos e de acordo com procedimentos formais e imparciais (MERTON, 1978, p. 108).

Cohen e March (1974) admitem a aplicação do modelo burocrático à universidade pois esta é uma organização com objectivos bem definidos, especificados por alguns grupos formais nela constituídos e que a sua tecnologia está bem definida e largamente compreendida. Afirmam que "a universidade está organizada numa hierarquia de autoridade e de tarefas com vista a realizar eficientemente os seus objectivos" (p. 31). Os seus membros concordam em perseguir estes objectivos em troca de vários tipos de recompensa.

Para Baldridge (1971, p. 11) existem muitos elementos burocráticos na organização universitária como a hierarquia formal de cargos e de autoridade que define um sistema de relações formais de autoridade. Outro aspecto é a existência de uma política interna e de regulamentos formais que regulam o trabalho da instituição, gerando um clima de conformidade. Este autor reconhece que a estrutura universitária se encontra dividida em órgãos (senado, conselhos, faculdades, departamentos) que mantêm entre si determinado tipo de relações formais hierárquicas, regidas por normas e regulamentos.

Outras características que reforçam a imagem burocrática da universidade foram identificadas por Baldridge (1971, p. 10) tais como: a nomeação dos responsáveis segundo o critério de competência; o pagamento de salários fixos e a exclusividade da carreira; o estilo de vida dos membros centrado à volta da organização, constituindo, por vezes, aquilo a que Merton (1978, p. 116) designou de "espírito de corpo"; a existência de graus e categorias hierárquicas definindo uma carreira; a presença de canais formais de comunicação. Por sua vez, Millett (1978, p. 17-18) destacou características burocráticas da universidade referindo-se à divisão formal de trabalho entre os departamentos e à hierarquia administrativa de cargos e responsabilidades. Lutz (1982, p. 166- 
167) vê na existência das comissões, dos relatórios exigidos e produzidos, dos prazos e horários a cumprir, dos processos de promoção docente, da outorga de graus académicos e dos controlos efectuados, evidências de que a universidade é uma organização burocrática. Embora reconheça o aspecto colegial inerente à universidade, Becher $(1988$, p. 318) destaca como elementos burocráticos a estruturação hierárquica dos cargos e da autoridade, os níveis de responsabilidade, as cadeias de comando, os regulamentos e papéis claramente definidos e a estrutura de órgãos e comissões.

Segundo a lógica burocrática não se reconhece aos actores organizacionais a sua liberdade estratégica, negligenciando-se a sua intervenção na organização. Estes são percepcionados como "executantes de papéis" na base de um "determinismo normativo" (CROZIER; FRIEDBERG, 1977, p. 101) uma vez que tais papéis prescrevem o comportamento aceitável. Numa estrutura dominada pela racionalidade burocrática, os actores são geralmente considerados passivos, cumpridores de papéis e executando as tarefas pelo mínimo segundo regras definidas. É-lhes atribuído um comportamento conformista, numa visão minimalista que tende a considerar o pessoal como um meio de produção (TÉRENCE, 1994, p. 25) ou peões que se integram numa estratégia de institucionalização da passividade.

\subsection{Perspectiva política}

Segundo esta perspectiva as organizações podem ser entendidas como "sistemas políticos em miniatura" (BALDRIDGE et al, 1978, p. 34; MARCH, 1991, p. 17), "organizações ou entidades políticas complexas" (BACHARACH, 1988, p. 281) ou "arenas de luta e liberdade" (ESTÊVÃO, 1998, p. 186) onde existem grupos de interesse e conflitos similares aos da sociedade mais geral. Bolman e Deal (1989) argumentam que a perspectiva política leva a considerar as organizações como coligações de indivíduos e grupos de interesse que diferem entre si quanto aos valores, preferências, crenças e percepções da realidade. Os mesmos (1989, p. 109) sintetizam a perspectiva política em cinco proposições básicas cuja combinação conduz à inevitabilidade do conflito e à centralidade do poder enquanto recurso usado estrategicamente (AHRNE, 1997, p. 118) e como factor determinante do resultado do jogo organizacional. São as seguintes: (i) existência de escassos recursos; (ii) existência de coligações de interesses; (iii) prevalência de divergências entre os indivíduos/grupos; (iv) definição de objectivos a partir da negociação de interesses; (v) face aos escassos recursos, eclode o conflito na vida organizacional. 
Recorrendo à análise política, Pugh et al (1971, p. 5) consideram que as organizações são cenários da actividade política na qual os indivíduos e os departamentos competem e cooperam pelo poder. Esta ideia é congruente com a hipótese de que o sistema é constituído por vários grupos de interesse que têm preferências e exigências diferentes e que se digladiam em busca de recursos de poder. Supõe que as decisões são tomadas graças a coligações de grupos de interesse e que cada coligação exerce um certo controlo potencial sobre o sistema (PUGH et al, 1971, p. 27). Neste sentido, a organização é encarada como um espaço de confrontação onde cada actor ou grupo utiliza estrategicamente a sua margem de liberdade explorando em seu proveito as "zonas de incerteza" visando a concretização dos seus objectivos (CROZIER; FRIEDBERG, 1977, p. 72) pelo que a acção colectiva se desenvolve como um "jogo de poder". Com efeito, a formulação das políticas é o resultado de negociações que decorrem em função do poder relativo de cada grupo e, de acordo com Birnbaun (1988, p. 144), "provavelmente será o subproduto resultante de muitas forças, e pode ser nem o pretendido nem o preferido por qualquer dos participantes".

O poder torna-se um factor determinante das estratégias dos indivíduos e grupos derivando daqui a concepção do "homem político". Assim, o poder, tal como Friedberg (1995) o concebe, é um fenómeno que estrutura os sistemas de acção concretos que marcam a dinâmica organizacional na qual, de acordo com Becher (1988, p. 320), os participantes são concebidos como actores políticos, o processo é visto como encenação política e o contexto da decisão como arena de luta.

A imagem política das organizações educativas sugere, segundo Bacharach (1988, p. 282-285), constantes lutas pelo poder com vista à obtenção de controlo sobre recursos reais ou simbólicos. A compreensão das organizações como sistemas políticos admite que elas funcionam segundo uma "racionalidade política" (LIMA, 1992, p. 59). Neste contexto, as organizações educativas são compreendidas como "contextos sociais atravessados por relações de poder" (AFONSO, 1991, p. 22), em que os indivíduos e os grupos usam os seus interesses e recursos de poder para influenciar a tomada de decisões. A este processo Bacharach e Lawler (1980, p. 1) designaram de actividade política, definindo-a como "o uso do poder para conservar ou obter controlo de recursos reais ou simbólicos".

Poder, pressão, regateio e negociação são termos usuais na descrição dos sistemas políticos em detrimento da ordem e da cooperação (Baldridge, 1971, p. 26). Neste contexto, prevalece o confronto entre as estruturas formais da organização e as informais, processo que Crozier (1963, p. 220-221) definiu 
como a "estratégia da incerteza" na qual o poder pode assumir formas discricionárias quer tenha por origem a estrutura formal ou a informal. Assim, quanto mais relevante for o factor humano maior será a "zona de incerteza normativa", desenvolvendo-se o poder dos subordinados. E quanto maior a força normativa maior será a capacidade de controlo sobre os participantes e maior o poder da administração.

Baldridge et al (1978, p. 35) chamam a atenção para alguns aspectos do processo político e que se resumem no seguinte: (i) a organização está fragmentada em grupos de interesse com diferentes objectivos e valores, que entram em conflito quando os interesses colidem; (ii) o conflito é um estado normal de que resultam as decisões políticas, sendo um indicador de "saúde organizacional" (BUSH, 1986); (iii) a autoridade legal é limitada devido à pressão exercida pelos grupos, de tal forma que as decisões acabam por ser o resultado de compromissos negociados entre si; (iv) a participação dos actores é fluida pois entram e saem do processo consoante o achem útil ou não.

Nesta perspectiva, a visão da universidade centra-se nos actores e nas coligações e a dinâmica organizacional é impulsionada pelos conflitos e sua resolução, pelas preferências políticas e pela mobilização do poder para fortalecer as exigências dos actores (BALDRIDGE et al, 1978, p. 71-73). O modelo político produz, segundo Baldridge (1971, p. 204) uma conceptualização adequada da dinâmica da universidade, privilegiando as estratégias políticas dos actores e a sua luta pelo poder pelo que estes podem ser vistos como agentes estrategas movimentando-se para exercer influências, pressionar os grupos opostos, negociar acordos e gerar compromissos. Isto sugere uma imagem de um jogo político em que a discórdia (MORTIMER; McCONNELL, 1978, p. 185-186) é permanente, o que apela à negociação com vista à tomada de decisões consensuais.

\subsection{Perspectiva institucional}

Nesta perspectiva reconhece-se às organizações a capacidade de promover a integração, o equilíbrio e a estabilidade social, sobrevalorizando a dimensão do ajustamento individual às estruturas, normas e sistemas ordenados e são enfatizados os quadros intersubjectivos da acção humana, o ajustamento e conformidade e a construção de mitos racionalizados para dar sentido à acção. Ferreira et al (2001, p. 145) consideram que "As instituições passam a ser concebidas como produto das construções dos indivíduos em interacção de onde não está ausente nem a possibilidade de conflito nem a de mudança e inovação". 
Estes autores sintetizam as características desta abordagem em quatro aspectos: (i) o enfoque analítico centra-se na acção, sobretudo no plano representacional dos sujeitos, bem como no processo dinâmico de institucionalização; (ii) as instituições são constituídas e moldadas por regras, classificações, esquemas e rotinas que assumem um papel simbólico na estrutura formal e que decorrem do hábito e das tipificações socialmente definidas e partilhadas; (iii) o Estado, os valores e a cultura da sociedade têm influência estruturante no processo de institucionalização das organizações; (iv) a institucionalização do comportamento humano permite a realização das actividades de forma estável e continuada porque existe uma conformidade social tácita perante pressupostos e princípios partilhados.

Os modelos institucionais mais referidos são o de Powell e Dimaggio (1991) e o de Meyer e Rowan (1977). O primeiro pretende explicar as razões de uma crescente homogeneidade organizacional ao nível da estrutura e das práticas. Defende que as organizações, por se encontrarem imbuídas no ambiente institucional, são resposta e reflexo das regras e padrões legitimados. Este modelo põe em evidência o conceito de isomorfismo para descrever as semelhanças estruturais das organizações, questionando a homogeneidade. O segundo propõe o entendimento das estruturas formais das organizações como mitos racionalizados e institucionalizados que são adoptados de forma cerimonial.

Para Hofstede (2003, p. 22) os símbolos como palavras, gestos, figuras ou objectos transportam um significado particular que é reconhecido pelos que partilham a cultura. A linguagem, a forma de trajar e os símbolos de estatuto pertencem a essa categoria. Santos Guerra (2002, p. 30-31) destaca essas características organizacionais na forma de configurar os cenários, as cerimónias e a linguagem usada na organização. Assim, o poder hierárquico pode ser expresso fisicamente através da distribuição dos espaços, sua localização e tamanho relevando a ordem hierárquica. Os ritos cerimoniais configuram-se como espaço propício para a expressão do poder e da hierarquia onde sobressaem modos de comunicação, gestos e indumentária. Por sua vez, a linguagem adquire certa conotação, comportando significações ou torna-se esotérica, sendo inacessível a pessoas estranhas à organização.

As organizações integram um conjunto de elementos peculiares pois "os mecanismos do poder instalam-se na sua cultura e dela recebem sentido e significados através de crenças, rituais, costumes, símbolos e rotinas. Para perscrutar esses significados é preciso contemplar a vida da organização, contextualizar os comportamentos, analisar as representações e estabelecer as redes de significados" (SANTOS GUERRA, 2002, p. 184). Estêvão (2004, 
p. 59) explica que, como sistema, a escola revela o seu carácter institucional e auto-regulado em que as funções dos seus membros são definidas mediante normas oficiais.

Para Dias Sobrinho (2008, p. 31) “A institucionalização é a organização das relações sociais e de trabalho e o exercício da democracia em toda a estrutura formal da Universidade”. Nesta ordem de ideias, a universidade pode ser analisada a partir dos processos, padrões, valores, significados, rituais, crenças e formas de pensamento que caracterizam a sua forma peculiar enquanto instituição e constituem, segundo Scott (1995, p. 34), a referência para a regulação das condutas. Significa que a universidade cria uma imagem própria a partir de um padrão, mediante o qual passa a ser encarada pela sociedade.

A construção da imagem da universidade obedece a estratégias para a tornar visível à sociedade. Nesta conformidade, a universidade abre as suas realizações ao público através de rituais académicos com notoriedade pública. O conjunto desses elementos passa a integrar a marca da universidade que lhe confere a imagem de instituição. Geralmente, as organizações constroem mitos que traduzem o modo como pretendem ser vistas. Como referem:

as organizações tendem a ajustar-se aos seus respectivos enquadramentos incorporando os mitos aí existentes; aderem a um sistema de narrativas, crenças e práticas dominantes na sociedade que, mesmo que sejam insuficientemente compreendidas, é aceite como certo (FERREIRA et al, 2001, p. 150-151).

A imagem criada pela organização, ao ser institucionalizada, pode ajudar a projectá-la socialmente mesmo que não corresponda à aç̧ão concreta. Ao assumir uma imagem que não possui na realidade, isso pode levar a uma "degradação dos valores académicos, uma desvalorização da exigência de qualidade em função da dinâmica credencialista" (DIAS SOBRINHO, 2008, p. 23). Ao adoptar narrativas que expressam uma imagem de credibilidade, a universidade induz à naturalização dessa imagem. Se uma universidade é credível, pode usar esse atributo para reforçar a sua imagem ou pode, simplesmente, viver dessa imagem, explorando os potenciais da visibilidade. A construção de uma imagem vazia descredibiliza a organização mas os elementos socialmente reconhecidos são argumentos com os quais a organização constrói os mitos que reforçam a sua credibilidade social.

Os actores organizacionais são considerados executantes de papéis, produzindo respostas padronizadas, isto é, tendem a agir segundo representações partilhadas das acções, posteriormente interiorizadas e institucionalizadas, 
funcionando então como agentes institucionalizadores na medida em que thes cabe o papel de veicular as narrativas, crenças e mitos com que se constrói a imagem social e a credibilidade da própria universidade. As práticas institucionalizadas passam a constituir os scripts pelos quais os actores se orientam, reforçando o seu significado e conduzindo à conformidade, base da legitimidade pública com a qual a universidade pode granjear apoios e recursos (MEYER; ROWAN, 1992, p. 34).

\section{A AVALIAÇÃO À LUZ DAS TRÊS PERSPECTIVAS}

\subsection{Dimensão burocrática da avaliação}

A avaliação institucional contém uma dimensão burocrática, já que lhe é inerente uma certa racionalidade a priori, decorrente da necessidade de especificação de objectivos e outros aspectos inerentes à burocracia, como o recurso a especialistas, a distribuição de tarefas, a hierarquização, a regulamentação e a normatividade do processo. Esta natureza burocrática evidencia-se pelo facto de ser "um processo socialmente organizado e promovido por actores sociais com legitimidade e competência técnica, ética e política institucional conferidas e reconhecidas" (DIAS SOBRINHO, 2000, p. 114). Ao explicar a intervenção dos actores no processo de avaliação, este autor considera que agem fazendo uso de instrumentos, critérios e metodologias construídas em função dos objectivos previstos e tornados públicos. Portanto, a avaliação institucional é um processo que se desenvolve com base em normas legalmente estabelecidas e segundo elementos técnicos e metodológicos devidamente documentados. Dias Sobrinho (2000, p. 115) lembra que "a avaliação institucional é um processo intencional [...], um conjunto coerente de conceitos, estruturados e implementados" com base numa determinada racionalidade.

Em relação à decisão no contexto da avaliação, House (2000, p. 30) diz que, independentemente do tipo de avaliação, a sua configuração inclui a identificação do nível de decisão, a definição de critérios de cada situação e as normas que regulam o processo de avaliação, bem como a especificação de tarefas. Deste modo, a avaliação surge como prática geralmente desencadeada sem negociação, de cima para baixo, desenvolvendo-se segundo regras e critérios definidos externamente, situação que decorre do controlo burocrático e do poder dos órgãos centrais. A avaliação, na óptica burocrática, surge quase sempre, embora sob a máscara do desenvolvimento profissional e institucional, com um carácter de controlo e de sancionamento. É muito formalizada, baseada em 
fichas e formulários, na produção de relatórios o que tende a conferir-lhe "uma objectividade apenas formal pois esquece a importância dos contextos e das variáveis informais no desenvolvimento dos processos educativos" (ROCHA, 1999, p. 30-31). Significa que a avaliação se apresenta como obrigação, dado que visa cumprir uma exigência legal, o que implica o uso de instrumentos de controlo para determinar o grau de cumprimento dessas exigências em relação ao modelo pré-definido.

A avaliação na universidade configura-se como categoria imprescindível partindo da ideia de que "A instituição precisa saber, de forma permanente e integrada, quais são os valores dominantes nas suas atividades de ensino, pesquisa e extensão e nas suas práticas administrativas" (DIAS SOBRINHO, 2008, p. 33). Ora, a avaliação institucional, por um lado, aparece como um instrumento impregnado de características burocráticas (rigidez na regulamentação, hierarquização) e, por outro, como um instrumento que reforça a imagem burocrática da universidade (hierarquia e controlo). Esta natureza burocrática pode ser ainda entendida a partir do seu lado formal, o carácter hierárquico, a impessoalidade e a regulamentação explicitada nos documentos jurídico-normativos que lhe servem de base. Dias Sobrinho (2003, p. 47), ao referir-se à avaliação interna, recorda que "todos os dados essenciais e pertinentes e as apreciações e críticas devem ser consolidados em relatórios, os quais, uma vez discutidos e aprovados pela comunidade, tornam-se documentos oficiais". Nota-se que, por um lado, a legitimidade da avaliação é assegurada pelas normas formais e, geralmente, obrigatórias, que determinam a previsibilidade do funcionamento da mesma e do comportamento dos actores envolvidos. Por outro lado, o próprio processo de avaliação resulta em procedimentos burocráticos, já que os documentos formalmente aprovados passam a ser considerados documentos oficiais da instituição.

Dias Sobrinho (2008, p. 34) refere que a avaliação institucional contribui para a especificação dos papéis e compromissos dos actores organizacionais, reafirmando o sistema de valores dominantes, isto é, valores pedagógicos e científicos. A avaliação das instituições educativas "tende a ser identificada com a avaliação do desempenho dos seus membros visto que, por definição, se aceita que há um melhor modo ('científico' ou 'democraticamente' definido) de desempenhar e/ou de conduzir/desenvolver a organização-escola" (ROCHA, 1999, p. 30). Afonso e Estevão (1992, p. 85) enfatizam a impessoalidade e a procura objectiva dos resultados, no contexto de uma avaliação concebida de cima para baixo e pretensamente objectiva, já que se fundamenta também em formulários muito estruturados. 
Enquanto instrumento que reforça as características burocráticas da universidade, podem ser considerados dois aspectos fundamentais: (i) a avaliação institucional revitaliza a racionalidade institucional para, a partir daí, serem determinadas a eficiência e eficácia da organização; (ii) a avaliação institucional produz conhecimento sobre as diversas estruturas académicas e administrativas da instituição, instaurando-se como um instrumento de melhoria da qualidade de todos os aspectos e sectores da organização.

No dizer de Rocha (1999, p. 30), a avaliação da escola numa perspectiva burocrática é realizada "com ênfase para a eficiência definida em termos dos procedimentos efectuados e da relação entre os resultados efectivamente atingidos e os que se deveriam ter conseguido”. Esta ideia realça quer a avaliação do processo quer a avaliação do produto. A avaliação, enquanto processo burocrático, implica a apreciação do grau de consecução dos objectivos tendo em conta padrões previamente estabelecidos e outros referenciais contidos no plano de desenvolvimento institucional.

\subsection{Dimensão política da avaliação}

A avaliação institucional revela uma dimensão política ao admitir o jogo de poder nas suas distintas fases. Nela manifestam-se interesses divergentes dos actores envolvidos pois os órgãos de gestão, embora conferindo à avaliação o carácter de desenvolvimento profissional e institucional, podem, às vezes, usá-la como instrumento de poder, de controlo e de sancionamento. Rocha $(1999$, p. 38) explica a natureza política da avaliação referindo que "a avaliação das escolas, ao 'mexer' nesse poder, interfere nos interesses, motivações e objectivos dos actores educativos, que são não só conflituantes mas, por vezes, mesmo opostos”. A avaliação assume esse papel quando usada pelos gestores para tomar decisões quanto à progressão dos docentes, penalizações ou despedimento. Para os avaliados, a avaliação poderá adquirir uma conotação negativa, sendo entendida mais como instrumento de controlo do que como mecanismo de desenvolvimento profissional.

No contexto da avaliação pode-se tentar uma aproximação dos interesses em jogo ou engendrar a submissão de uma das partes. Isso decorre do facto de as normas estabelecidas para regular a avaliação não acomodarem todos os interesses, significando que os espaços de incerteza subsistem, o que cria a possibilidade de os actores explorarem tais incertezas a favor da viabilização dos seus interesses. Assim, existem pontos de tensão que decorrem do esta- 
tuto que os actores assumem - de avaliador ou de avaliado. Nessa relação, o avaliador é investido de certo poder já que a ele cabe o papel de, a partir das informações recolhidas, aferir a qualidade de determinados processos e tomar decisões que afectam os outros.

A titularidade da avaliação coloca em confronto a autonomia auferida pelas universidades públicas financiadas pelo Estado e o papel avaliador e controlador deste. Nessa relação, o Estado é detentor da capacidade de impor a sua vontade, fundamentada na necessidade de controlo dos investimentos e na comprovação dos níveis de realização dos objectivos, pois a "avaliação deveria fornecer bases para análises de carácter político" (DIAS SOBRINHO, 2003, p. 55). O Estado, enquanto financiador, vê-se no direito de desencadear a avaliação das universidades, visando obter informações que lhe permitam avaliar a relação custo-benefício e avaliar até que ponto as suas políticas estão a ser preservadas nos objectivos e nos produtos das universidades.

O Estado pode ter interferência directa no estabelecimento dos critérios de avaliação e na selecção dos avaliadores o que, como Santos Guerra (2002, p. 190) refere, lhe confere a titularidade da avaliação. Portanto, a avaliação das universidades revela-se como instrumento através do qual o Estado exerce controlo sobre a acreditação e funcionamento destas, em defesa das políticas educativas nacionais. Day (2001, p.150) considera que os sistemas de avaliação são importantes para promover o desenvolvimento das instituições educativas, encontrando-se implícitos tanto os aspectos relacionados com os currículos, as necessidades dos alunos, bem como as exigências quanto ao processo de formação.

Os aspectos conflituais da avaliação convertem-na num cenário onde os actores confrontam os seus interesses e objectivos. No palco pluralista da avaliação institucional a negociação é evidenciada de forma implícita uma vez que os actores organizacionais são envolvidos nesse processo de diálogo e confrontação. O nível de envolvimento dos actores influencia de forma considerável o processo de avaliação, já que deve existir acordo quanto aos seguintes aspectos: o quê, como, quando e a quem compete avaliar. No dizer de Sguissardi (1996, p. 127),

Este acordo, e somente ele, pode garantir o início e eventual êxito desse processo, sem que com isso se desconsidere eventuais atitudes de resistência e de auto-defesa decorrentes da associação da avaliação a ideias tantas vezes presentes de auditoria e de punição. 
O acordo resultante da negociação é um aspecto do qual depende o êxito do processo, o que leva a considerar a necessidade da participação dos actores, "entendida como a actuação responsável dos diferentes segmentos institucionais em todas as fases do processo de avaliação" (SGUISSARDI, 1996, p. 130). Para Castro-Almeida et al (1993, p. 122)

A função participativa implica que os resultados de cada avaliação sejam restituídos aos actores e responsáveis do projecto, não ficando reservados para os organismos financiadores ou para as autoridades do país".

Este procedimento assegura a participação dos avaliados dado que suscita debate e uma análise crítica dos resultados obtidos, assegurando uma certa responsabilização e compromisso dos actores.

A avaliação participada não exclui a intervenção de actores externos à universidade mas coloca, de acordo com Lafond (1999, p. 13), a necessidade de um trabalho em parceria para se assegurar a legitimação da própria avaliação interna, pois

o estabelecimento de ensino não pode funcionar como uma redoma.
Tem contas a prestar à autoridade de tutela, aos pais, à opinião pú-
blica. Entregue a si próprio, corre o risco de se iludir, de se enganar
a si mesmo. Para que a auto-avaliação seja fiável é necessário que se
apoie em referências objectivas, em indicadores e, sobretudo, que seja
validada por uma observação exterior. Esta última, organizada e com-
petente, legitimada pela autoridade de tutela, é a avaliação externa.

A complementaridade entre avaliação externa e interna e a envolvência de actores internos e externos obriga a estabelecer acordos que permitem regular e legitimar o processo, sendo importante que a condução do mesmo respeite a autonomia confiada à instituição a avaliar. Sob a perspectiva política a avaliação institucional fundamenta-se no reconhecimento da pluralidade de interesses não excluindo a possibilidade de que os diferentes actores e grupos envolvidos "sejam levados a redefinir os seus projectos, perspectivas e interesses e a inserilos num referencial comum a toda a comunidade implicada" (RODRIGUES, 1999, p. 47) mediante negociação.

\subsection{Dimensão institucional da avaliação}

Na perspectiva institucional a avaliação inscreve-se nos processos de construção das narrativas e crenças sobre o universo académico, ajudando a refor- 
çar a dimensão da complexidade e esoterismo que o caracteriza, bem como a áurea de sapiência própria da universidade. A avaliação configura-se como um exercício simbólico que não só contribui para visibilizar os rituais académicos como para construir a credibilidade que resulta dos processos avaliativos bem sucedidos. O processo de avaliação obedece a rituais que integram a tomada de posse dos agentes avaliadores, a publicitação das normas, dos instrumentos e dos resultados, concorrendo para a legitimação interna e externa da universidade e dos seus actores na medida em que, pela avaliação se afiança a imagem de instituição credível ou, pelo menos, serve para anunciar que foi "certificada", decorrendo daqui uma imagem social favorável.

Neste sentido, a avaliação tem uma importância crucial na definição da relação com a comunidade, servindo, na base dos resultados produzidos, para apresentar os seus méritos e captar os públicos nela estão interessados, para além de gerar um clima de confiança nos empregadores de quem se espera que absorvam os diplomados. Na verdade, os processos de avaliação das aprendizagens e do desempenho da instituição constituem um elemento importante para criar confiança nos "produtos" da universidade, o que vem estimular a procura social e contribuir para gerar a necessária credibilidade social.

Dias Sobrinho (2003, p. 46) explica que o processo de avaliação deve ter certa legitimidade, isto é, deve ser configurado e desenvolvido com base nas determinações e na cultura de cada instituição, isto é, a avaliação deve ser formalmente institucionalizada e deve submeter-se aos critérios instaurados em processos comunicativos que envolvem a comunidade universitária. Decorrente destas características institucionais reconhece-se que nenhuma universidade sobrevive e assegura a sua legitimação sem um processo de avaliação institucional que, num contexto de competição, aparece como factor de credibilização e de legitimação social. Portanto, a avaliação participativa e democrática apresenta-se como um dos formatos que mais se aproxima das características da abordagem institucional.

A avaliação torna-se imperiosa para verificar e dar consistência aos mitos associados à universidade (sede do saber, factor de desenvolvimento, "viveiro" de quadros, etc.) e para reforçar a sua legitimação social. Nesta perspectiva, a avaliação caracteriza-se fundamentalmente pela participação institucional, ou seja,

A comunidade universitária deve participar institucionalmente desse processo, tanto nas discussões sobre a concepção, as finalidades e o desenho da avaliação, quanto no levantamento e organização das 
informações e dados quantitativos, nas pesquisas, interpretações e valorações de carácter qualitativo (DIAS SOBRINHO, 2003, p. 47).

O envolvimento e a participação dos diferentes actores favorecem a criação de uma predisposição para encarar a avaliação como algo útil e necessário ao mesmo tempo que gera dinâmicas de "promoção da qualidade" o que reforça publicamente a imagem de seriedade e rigor com que se constroem as narrativas de uma instituição universitária credível e preocupada com um melhor serviço público de educação.

Num contexto em que se torna necessário consensualizar modos de compreensão acerca da importância da avaliação no que diz respeito à produção de elementos que reforcem o significado do trabalho académico, a avaliação institucional pode ser usada para construir o sentido do que é estar na universidade uma vez que, através dela, se pode instituir uma "cultura académica" na qual a avaliação seja encarada como prática de diálogo interpares, servindo de elemento aglutinador. Independentemente das representações sobre a avaliação, procura-se que os actores partilhem significados que hão-de conferir o sentido legitimador da avaliação a partir do qual todos se reconhecem como membros de uma comunidade, gerando o que Scott (1995, p. 45-47) designou de "conformidade institucional".

A avaliação institucional constitui uma possibilidade de gerar um autoconhecimento acerca do grau de aproximação às expectativas sociais e, nessa base, adoptar medidas atinentes aos processos formativos que permitam aperfeiçoálos de forma a melhorar a sua qualidade tendo em conta as demandas sociais. Com isto, a universidade revela a sua responsabilidade social, tornando-se uma força operante e um parceiro da governação local (PINTO, 1998, p. 44). Smith (2007, p. 30-31) inclui nesta noção de responsabilidade social o compromisso da universidade face ao contexto cultural, às demandas da economia, à formação de profissionais, à produção de conhecimento e à educação dos cidadãos. Para Santos $(2008$, p. 61-62, 76) a responsabilidade social da universidade decorre do seu reconhecimento como "espaço público" e "bem público ligado ao projecto de país", o que implica que esta deve ser permeável às demandas sociais. Mesmo que assim não seja, ao enunciar estas intenções, a universidade cria condições para ser encarada como instituição indispensável, podendo os resultados da avaliação institucional, quando favoráveis, contribuir para reforçar esta imagem. Em contexto de valorização da qualidade como condição de aceitação social, a avaliação converte-se no mecanismo através do qual a universidade se afirma como instituição útil e factor de desenvolvimento social, conquistando um lugar de charneira no tecido social. 


\section{A AVALIAÇÃO INSTITUCIONAL NA UNIVERSIDADE AGOSTINHO NETO}

As iniciativas no campo da avaliação institucional na UAN surgiram nos finais da década de 80, como avaliação externa, ao passo que algumas práticas episódicas de avaliação interna se reportam a 2005. As práticas de avaliação interna desenvolveram-se por iniciativa própria num quadro de ausência de uma política nacional de avaliação. Na legislação actual que regula o sistema de educação em Angola, são encontradas referências explícitas a uma política nacional de avaliação institucional. Na Lei de Bases do Sistema de Educação (Lei $\mathrm{n}^{\circ}$ 13/01, de 31 de Dezembro) estabelece-se que este "é objecto de avaliação contínua com incidência especial sobre o desenvolvimento, a regulação [...]" (Art. 63). O Estatuto do Ministério do Ensino Superior e da Ciência e Tecnologia - MESCT (Decreto Presidencial no 70/10, de 19 de Maio) define como atribuições "promover o desenvolvimento, a modernização, a qualidade, a competitividade e a avaliação do subsistema de ensino superior [...]". Assim, as práticas de avaliação na UAN sustentam-se uma política de avaliação que ganha sentido no quadro das mudanças operadas no subsistema de ensino superior em Angola.

Na UAN, as práticas relacionadas com a avaliação institucional estão associadas a representações que lhe atribuem um sentido legitimador e de credibilização da imagem institucional. Assim é que a avaliação interna na FMUAN foi accionada no sentido de conferir legitimidade ao processo de reforma curricular. Por outro lado, nota-se a tendência para a legitimação da avaliação institucional através de processos colegiais (aprovação em Senado e Assembleia da UAN) do mesmo modo que se estabelece uma certa padronização em termos de procedimentos metodológicos para a concepção e implementação da avaliação interna. O apelo à representatividade e ao rigor na selecção dos integrantes das comissões de avaliação interna, privilegiando a qualificação académica e a experiência profissional manifesta a necessidade do envolvimento de agentes credíveis.

Houve intenção de envolver no processo os diversos actores organizacionais internos, a julgar pela tendência de se divulgar e abordar o assunto, de forma específica, no Conselho Científico e em contacto directo com os departamentos, bem como a apresentação do projecto de avaliação interna aos actores organizacionais externos, como a Ordem dos Médicos, o Ministério da Saúde e as Organizações não Governamentais. Apesar da fraca participação dos actores organizacionais no processo de avaliação, há preocupações em relação à legiti- 
mação do processo, através da anuência de fóruns colegiais, como o Conselho Científico, o Senado e a Assembleia da universidade, embora nem sempre se possa garantir a legitimidade institucional dos avaliadores por alegada falta de competência destes.

A documentação de base sobre a avaliação interna das estruturas orgânicas da UAN estrutura-se segundo racionalidades que sobrevalorizam a dimensão quantitativa da avaliação sem precisar aspectos essenciais como para quê e como avaliar. Procura-se aferir a qualidade dos cursos a partir da análise assente numa perspectiva mais quantitativa, com certa sobrevalorização da análise ao processo de ensino-aprendizagem.

Relativamente às representações sobre a avaliação, persistem ambiguidades dado que não é encontrada nos documentos oficiais uma definição que permita uma compreensão clara da concepção de avaliação e um entendimento unívoco por todos os actores organizacionais. A relevância atribuída à avaliação das aprendizagens indica uma tendência para o enquadramento da avaliação dos cursos, deixando de parte a avaliação institucional. A definição do referencial da avaliação interna e a sua especificação em indicadores de qualidade mostra-se adequada, apresentando sete variáveis: (i) pertinência, impacto e finalidade, (ii) perfil profissional, (iii) currículo, (iv) recursos humanos, físicos e financeiros, (v) processo de ensino-aprendizagem, (vi) investigação científica e (vii) organização e gestão, que ajudarão a conhecer a qualidade dos cursos ministrados.

Em termos de constituição, as comissões de avaliação denotam representatividade, pois incluem actores organizacionais e agentes externos. Ao nível interno são incluídos representantes dos corpos docente, discente e administrativo. Na configuração de um sistema de avaliação interna da UAN é perceptível o reconhecimento, por parte dos gestores, docentes, discentes e funcionários, da necessidade e da importância do estabelecimento de um sistema de avaliação que vise o controlo e a garantia da qualidade ao nível do ensino-aprendizagem e da gestão. Nota-se uma tendência para considerar a avaliação interna como um processo obrigatório, relacionado com o facto de a UAN existir há mais de 30 anos, o que implica a necessidade de obtenção de uma percepção sobre a eficácia da acção organizacional como base para a concepção do plano de acção para a projecção da melhoria.

\subsection{Avaliação externa na UAN}

Entre as experiências estruturadas mais relevantes de avaliação externa da UAN encontram-se quatro estudos: (i) o da Fundação Calouste Gulbenkian 
(1987); (ii) o da Fundação Gomes Teixeira, (Junho de 1995 a Março de 1996); (iii) o diagnóstico realizado pela SEES (em 2005), enquanto órgão do Governo "encarregue do planeamento, orientação, coordenação, supervisão do processo de formação e implementação da política para o desenvolvimento do ensino superior" (Decreto-Lei 2/09, de 29 de Abril) e (iv) a avaliação externa da Faculdade de Medicina da UAN, realizada pela Universidade do Porto (em 2007).

O primeiro, de acordo com o respectivo relatório (1987, p. 8-9), visou analisar a situação da UAN e definir o quadro de prioridades e de acções de cooperação a desenvolver no âmbito do programa de apoio da referida Fundação à UAN. Os principais pontos de estrangulamento do funcionamento da UAN eram: (i) insuficiência de recursos (humanos, físicos e financeiros); (ii) excessiva dependência externa, decorrente da carência de quadros angolanos qualificados e diferenciados; (iii) fraca dignificação e reconhecimento da instituição e (iv) impreparação dos estudantes e inadequação do seu estatuto.

Em função desses pontos de estrangulamento foram definidos quatro objectivos prioritários para o desenvolvimento da UAN: (i) promover a melhoria da qualidade; (ii) desenvolver a capacidade humana a todos os níveis; (iii) reorganizar os departamentos que prestam serviços estrategicamente relevantes e (iv) criar as condições materiais que possibilitem um desenvolvimento auto-sustentado.

$\mathrm{O}$ segundo estudo procurou identificar aspectos relacionados com o funcionamento interno e o relacionamento da universidade com o meio envolvente, focando o relacionamento com os restantes graus de ensino, a capacidade de formar quadros e a sua inserção no contexto científico e cooperação universitária. Na análise da dinâmica interna, foram considerados dois ângulos de observação, um longitudinal, atravessando toda a universidade e outro transversal, incidindo sobre cada unidade orgânica. O mesmo, assumindo-se como "uma avaliação externa da UAN" (FUNDAÇÃO GOMES TEIXEIRA, 1996, p. 22), permitiu fazer um diagnóstico rigoroso e esboçar um conjunto de propostas precisas e susceptíveis de modificar o panorama universitário angolano.

O terceiro estudo diz respeito a um diagnóstico realizado pela SEES, ao longo do ano de 2005, que analisou aspectos relacionados com a gestão universitária, tendo abarcado todas as instituições de ensino superior (públicas e privadas). Os resultados obtidos foram tomados como referência para a análise e projecção da melhoria de todo o subsistema de ensino superior, de que viria a resultar a reorganização da rede de IES, a criação de novas universidades públicas, bem como o redimensionamento da UAN.

O quarto estudo refere-se à avaliação externa da Faculdade de Medicina da UAN (2007), na base dos resultados da avaliação interna e tendo como referen- 
cial os Standards Globais para o Desenvolvimento de Qualidade em Educação Médica Pré-Graduada da Word Federation of Medical Education. Esta contou com a parceria da Faculdade de Medicina da Universidade do Porto e com a cooperação do Instituto Português de Apoio ao Desenvolvimento, marcando o início da implementação de um programa estruturante de desenvolvimento da qualidade da formação de médicos em Angola.

\subsection{Avaliação interna na UAN}

No que diz respeito à avaliação interna, existe apenas uma experiência estruturada que é a avaliação da Faculdade de Medicina (FMUAN). Conforme o relatório final de avaliação institucional da FMUAN (2006), o processo de avaliação incluiu a avaliação e diagnóstico do carácter científico-pedagógico do curso de licenciatura em Medicina, com o objectivo de "Descrever o Curso de Medicina e a Faculdade, durante o ano académico de 2005/2006, em termos de estrutura, processo e resultados”. Pretendeu-se com esta avaliação criar as bases para a direcção de um processo de reforma fundamentado e consequente.

Nessa experiência, a liderança, a estabilidade e as parcerias institucionais, a existência de referenciais específicos para a avaliação da qualidade, a criação oficial de uma comissão de avaliação interna são indicados como pontos fortes mais significativos, mas a inexistência de financiamento, o distanciamento da comunidade académica (incluindo actores internos), a percepção invertida do processo, fundamentalmente em relação às necessidades de reforma curricular, constam no Relatório da Avaliação Interna como pontos fracos.

Podem ainda ser referidas como práticas pouco estruturadas de avaliação interna, a avaliação do desempenho dos docentes e a avaliação do desempenho científico da instituição (UAN - Deliberação n ${ }^{0}$ 015/SU/2003). Para o primeiro caso, procurou-se apurar a qualidade do desempenho dos docentes a partir da análise de indicadores relacionados com as competências pedagógicas e científicas respeitantes à organização, execução e condução do processo docenteeducativo e resultados das aprendizagens. Os resultados dessa avaliação servem, fundamentalmente, para a promoção na carreira, podendo ainda servir para sancionar desempenhos insatisfatórios, sob proposta do Conselho Pedagógico da Faculdade.

No segundo caso, embora não existam evidências da aplicação desse instrumento, estão estabelecidos os procedimentos para a avaliação do desempenho científico de cada Unidade Orgânica (UAN, 2007, p. 150-153), centrados fundamentalmente na quantificação das actividades de carácter científico (número 
de publicações, apresentação de comunicações e relatórios de investigação e desempenho nos cursos de pós-graduação). O estabelecimento destes parâmetros pode constituir-se como indicador do grau de desempenho científico da instituição, sendo, no entanto, bastante superficial pois, na avaliação da qualidade do desempenho científico da instituição, "mais que contabilizar a produção científica de um pesquisador, é preciso avaliar os significados da pesquisa para a ciência, a formação humana e a sociedade" (DIAS SOBRINHO, 2003, p. 44). O mesmo autor (2000, p. 124) refere que a consideração do número de produções científicas, de forma isolada, não diz quase nada a respeito da qualidade da pesquisa, sua relevância social, sua articulação com o ensino e sua adequação com a missão da universidade.

Neste quadro, a avaliação interna afigura-se como um embrião que se espera vir a constituir uma prática sistemática em todas as Unidades Orgânicas da UAN. Tal ainda não ocorre devido à ausência de pressupostos legais e à inexistência de uma estrutura organizacional capaz de promover uma cultura permanente de autoconhecimento e auto-regulação ao nível das IES. Isto significa que as práticas avaliativas na UAN ainda são delimitadas e episódicas, incipientes e mal compreendidas, circunscrevendo-se a determinadas dimensões, neste caso à avaliação (parcial) do desempenho dos docentes.

No âmbito da avaliação interna é perceptível a tendência do controlo do processo por parte da hierarquia da instituição e, logicamente, o predomínio do papel dos gestores. Tal controlo foi marcante tanto na fase de concepção como na de implementação da avaliação externa, sendo evidente que, de acordo com o relatório do estudo (FUNDAÇÃO GOMES TEIXEIRA, 1996, p. 172), o lançamento dos questionários foi precedido de análise e respectiva autorização por parte da entidade máxima; os responsáveis acompanharam o preenchimento dos questionários e tiveram acesso aos mesmos após o preenchimento.

Constatou-se que os gestores assumem um protagonismo relevante nas comissões encarregues da avaliação, como sucedeu com a comissão de avaliação interna na FMUAN. Quanto à comissão para o aprimoramento da documentação sobre a auto-avaliação das estruturas da UAN, no caso da Reitoria, a sua composição indica algum desequilíbrio em termos de representatividade dos diversos actores, sendo maior para a classe dos gestores em detrimento da classe docente, dos discentes e dos funcionários administrativos. Assim, o processo foi assegurado pelos gestores e as apreciações basearam-se fundamentalmente na visão destes, excluindo da avaliação as perspectivas dos docentes. Não houve qualquer negociação acerca das dimensões, processos e juízos relativos à avaliação. 
Detecta-se uma lógica baseada no princípio do "Estado avaliador" ao ser institucionalizado o sistema nacional de avaliação das IES, seguindo a orientação de que o MESCT deve "promover a observação permanente, a avaliação e a inspecção das Instituições de Ensino Superior". Está, assim, criado um campo propício para o confronto de interesses entre o Estado e as IES que reivindicam autonomia, logo, maior intervenção neste processo.

Ao nível interno da UAN há características que evidenciam, nesta fase inicial, a tendência de se accionar mecanismos e instrumentos que visam a regulação e padronização da avaliação, como sendo: a estruturação de um Sistema Interno de Avaliação de Cursos, a concepção do Regulamento do Funcionamento das Comissões de Avaliação Interna, o estabelecimento de Procedimentos Metodológicos e Fases de Auto-avaliação, das Formas de Aferir a Qualidade dos Resultados e a concepção do Guia de Avaliação dos Cursos. Estando numa fase incipiente e tendo em conta a "quase inexistência de uma cultura de avaliação" nas IES, a padronização pode fazer algum sentido desde que se salvaguarde a contextualização e adaptação da avaliação a cada realidade concreta, processo que não está isento das influências resultantes dos jogos de interesse, daqui emergindo a sua natureza conflitual.

A avaliação interna está estruturada numa lógica em que os actores internos assumem um duplo estatuto: de avaliados e de avaliadores, contando com a assessoria de especialistas externos (Universidade do Porto e Universidade Técnica de Lisboa), tanto na fase de concepção como na de mobilização dos actores para o processo (através de dois seminários sobre avaliação interna, nos quais participaram os membros da direcção da UAN). Há que ressaltar uma certa preocupação com a legitimação e credibilização da avaliação interna, indo de encontro à opinião de Dias Sobrinho (2003, p. 46-47) quanto à necessidade de uma ampla participação da comunidade universitária interna e externa.

Em contexto de redimensionamento da UAN, a Reitoria volta a acentuar em 2009 a avaliação interna, entendida como processo fundamental para o balanço do mandato dos gestores e para a transferência de pastas às novas universidades públicas entretanto criadas em resultado do desmembramento daquela. Nesta perspectiva, foi realizado o "Conselho Consultivo sobre a Avaliação Interna", com realce para a apresentação da experiência da Faculdade de Medicina e da documentação de base para a implementação do processo.

O processo de avaliação interna não se consolidou como se previa. Assim é que, entre as conclusões saídas do Conselho Consultivo sobre a Avaliação Interna na UAN (2009), a avaliação realizada pela faculdade de Medicina persistia como experiência única apesar do apelo ao "início imediato do pro- 
cesso de avaliação interna nas demais Unidades Orgânicas da UAN”. Entre as fragilidades apontadas estão a não criação das designadas Comissões Técnicas de Apoio - CTA, ao nível das Unidades Orgânicas, bem como a inexistência de uma dotação financeira específica para a implementação do processo. Tal facto deveu-se à dificuldade de designar "avaliadores credíveis" num contexto de insuficiente diferenciação académica do corpo docente, gerando o não reconhecimento da legitimidade dos avaliadores. Por outro lado, houve resistências decorrentes de insatisfações dos actores não envolvidos, da exclusão dos seus interesses e das decisões que tal avaliação possa ter legitimado, julgando-se que esta poderia ser um instrumento de controlo ao serviço dos interesses dos gestores e, consequentemente, a não interiorização da utilidade da avaliação, perdendo-se o sentido da responsabilidade compartilhada. Por outro lado, o não reconhecimento da competência dos avaliadores internos gerou desconfianças em relação à qualidade da própria avaliação.

Quanto à avaliação do desempenho dos docentes sobressai o preenchimento de fichas de acompanhamento do trabalho docente em que participam estudantes e membros do Conselho Pedagógico da Unidade Orgânica, com efeitos na promoção na carreira docente. A referida avaliação tem-se baseado em apreciações difusas pelos pares, o que os leva a fornecer informações pouco consistentes sobre o desempenho dos avaliados. Esta maneira de avaliar, baseada na informalidade e no impressionismo cria um espaço propício à imposição de critérios e percepções dos que assumem o papel de avaliadores, cujas apreciações pessoais se baseiam no recurso aos acontecimentos mais recentes presentes na suamemória. Tal prática acentua a subjectividade da avaliação e leva a que os que detêm poder possam influenciar o processo de avaliação, conferindo-lhe um carácter de instrumento para punir ou premiar, mais do que instrumento ao serviço do desenvolvimento profissional e organizacional.

Essas práticas, não sendo formalizadas nem sistemáticas, tornam-se pouco consistentes, dando lugar a jogos de influência, tornando o processo pouco credível, volúvel, sujeito à arbitrariedade de quem tem poder e criando possibilidades para confrontos entre colegas e mesmo "ajustes de contas", com implicações no futuro profissional dos avaliados. O quadro pode tornar-se mais precário se não se puder garantir a transparência, o rigor e a ética avaliativa por parte de quem está investido das funções de avaliador, especialmente se este não estiver academicamente legitimado e se não se perceber que agenda está subjacente - prestação de contas, controlo institucional ou melhoria dos processos. 


\section{CONSIDERAÇÕES FINAIS}

Nos últimos anos tem sido questionada a qualidade do ensino superior em Angola pelo que se tem notado uma crescente preocupação do Estado em relação à necessidade de melhoria da qualidade do ensino superior. Por isso se tem invocado a avaliação institucional como caminho para a regulação do subsistema do ensino superior em busca da qualidade desejada. Assim, num contexto em que se reserva ao Estado o papel reitor na gestão do subsistema do ensino superior, este vem assumindo preponderância na avaliação institucional, colocando em causa a autonomia das universidades. No caso de Angola podem ser encontradas vários normativos nos quais se atribui à tutela competências como: "definir critérios gerais de avaliação do desempenho das instituições"; "criar mecanismos que assegurem a avaliação externa da qualidade dos serviços prestados"; "apreciar e avaliar o mérito da actividade e desempenho das instituições de ensino superior", bem como "homologar os regimes de avaliação interna das instituições de ensino superior" (Decreto $n^{\circ}$ 90/09, de 15 de Dezembro) o que confirma o princípio do "Estado avaliador".

Daqui resulta a configuração de um campo propício para a influência do Estado na concepção e implementação da avaliação institucional, já que esta deve ser confirmada ou aprovada pela tutela. Estas questões devem ser analisadas no âmbito da titularidade da avaliação que, na opinião de Santos (2008, p. 190) é a que mais subjuga a autonomia das universidades públicas financiadas pelo Estado, o que as leva a ceder à pressão para se deixarem avaliar, escapando-selhes a titularidade da avaliação. Neste jogo reflecte-se a crise institucional da universidade que, na opinião de Santos (1997, p. 17), “constitui o elo mais fraco da universidade pública porque a autonomia científica e pedagógica assenta na dependência financeira do Estado".

O percurso da UAN em termos de avaliação institucional revela que, nas primeiras experiências, o olhar externo deu lugar a processos de autoconhecimento, o que constitui factor significativo em processos de mudança institucional. Ristoff (2003, p. 29) considera que a imagem institucional construída de dentro para fora leva a um despertar da consciência sobre a imagem que se deseja projectar e colocar à disposição de avaliadores externos, o que responsabiliza os actores organizacionais face a necessidades de mudança de concepções e práticas. Esta lógica tem ainda sustentação quando a avaliação externa é entendida como um processo que "se realiza desde fuera del ámbito escolar y que pretende ofrecer a los componentes del sistema educativo, otro punto de vista que hay que añadir a la evaluación interna que ellos realizan (MEC, 1989 apud ARREDONDO, 2003, p. 84). 
Analisando as características dos processos de avaliação em curso na UAN é possível identificar elementos de natureza burocrática, política e institucional. Do ponto de vista burocrático assinale-se que o processo foi desencadeado de cima para baixo, com obrigatoriedade legal e segundo um modelo superiormente definido e imposto, cuja elaboração pouco beneficiou de contributos de gestores intermédios e docentes. Para regular o processo e garantir uniformidade, foi estabelecida uma metodologia padronizada que visava orientar a implementação das práticas avaliativas nas faculdades que, entre outras razões, tinha como fundamento a prestação de contas dos gestores em fim de mandado (decanos), os quais teriam de proceder à avaliação. Para estes, tratou-se de uma obrigação superiormente determinada à qual não poderiam escapar sob pena de sofrerem sanções.

A dimensão política da avaliação ficou expressa através da assimetria de poderes entre as estruturas envolvidas com destaque para as de topo que assumiram as decisões estratégicas. Além disso, nem sempre gestores e docentes partilharam os objectivos e os mecanismos adoptados. O processo de avaliação foi decidido na reitoria em função do quadro normativo e imposto às unidades orgânicas, decorrendo sob controlo quase exclusivo dos gestores e na base de orientações metodológicas provenientes de cima. Entre avaliadores e avaliados também existiram clivagens uma vez que não eram claras as intenções, havia receios quanto aos efeitos da avaliação e não existia confiança nos avaliadores. Para alguns deles, o poder de avaliar representou a assunção de um certo estatuto académico e factor de diferenciação numa carreira onde essa diferenciação é meramente administrativa. Isso significou também algum ascendente do ponto de vista do poder político e académico no interior das unidades orgânicas.

Um dos fundamentos da avaliação institucional na UAN residiu na necessidade de gerar uma base de informação capaz de consubstanciar a construção de uma imagem de credibilidade perante a opinião pública mas também de produzir um sentido institucional da qualidade educativa que sossegasse os gestores e docentes, ou seja, um elemento palpável que sustentasse a crença no mérito do seu próprio trabalho. Assim, os resultados da avaliação adquirem importância interna no sentido de reforçar o ego dos académicos mas, acima de tudo, externa, na medida em que servem para que a UAN se apresente como uma instituição credível e digna de confiança. No contexto da concorrência com as universidades privadas, a avaliação institucional constitui um símbolo que atesta o mérito institucional da UAN com o qual ela pode construir e consolidar a sua imagem social e captar novos públicos.

A institucionalização de um sistema de avaliação na UAN revela-se pertinente no actual quadro de reestruturação do subsistema de ensino superior em 
Angola, dada a responsabilidade que a UAN representa, enquanto "universidade-mãe", cuja afirmação social muito deve ao compromisso com a qualidade educativa. Pelo facto, a avaliação institucional deve ser assumida mais numa lógica de melhoria e desenvolvimento do que de prestação de contas e controlo, ao mesmo tempo que se instala a cultura da qualidade, o que passa pelo compromisso institucional com uma avaliação mais sistemática e rigorosa.

Partindo da dissociação entre as funções substantivas da universidade e a pouca relevância da avaliação institucional, os principais desafios da UAN em termos de avaliação institucional assentam nos seguintes aspectos-chave:

i. Configuração de um sistema de avaliação interna, com carácter mais participativo e inovador, segundo uma abordagem que promova a integração do trinómio ensino-investigação-extensão e que se consubstancie num processo prévio de formação de agentes avaliadores, tendente a credibilizar o processo;

ii. Concepção/adaptação de modelos ou padrões de avaliação que privilegiem a contextualização, em conformidade com a realidade e condições específicas de cada estrutura da UAN e segundo o princípio da integração nacional e regional. A avaliação institucional deve conformar-se às especificidades organizacionais sem excluir os padrões internacionais de referência, para salvaguardar a afirmação da UAN nos planos nacional e internacional;

iii. Criação de condições humanas, organizativas e financeiras para viabilizar um processo de avaliação credível que possa oferecer um retrato da UAN o mais objectivo e completo possível, numa lógica de desenvolvimento profissional e institucional e enquanto recurso para a credibilização social da própria universidade.

É preciso que a avaliação cumpra, para além das suas funções simbólica e de controlo social, relacionada com a selecção dos indivíduos, uma função estratégica de desenvolvimento profissional e organizacional, o que exige maior sustentação teórica para lhe conferir qualidade. Isso inclui a formação adequada dos agentes envolvidos e a adopção de práticas consistentes rumo à institucionalização de uma cultura da avaliação. 


\section{REFERÊNCIAS}

AFONSO, A. J. O processo disciplinar como meio de controlo na sala de aula. Braga: Instituto de Educação. Universidade do Minho, 1991.

AFONSO, A. J. Políticas educativas e avaliação educacional. Braga: Universidade do Minho, 1998.

AFONSO, A. J. Avaliar a Escola e a Gestão Escolar: Elementos para uma reflexão crítica. In: ESTEBAN, M. T. Escola, currículo e avaliação. São Paulo: Cortez, 2003.

AFONSO, A. Avaliação educacional. Regulação e emancipação: para uma sociologia das políticas avaliativas contemporâneas. São Paulo: Cortez, 2005.

AFONSO, A. J.; ESTÊVÃO, C. A. V. A Avaliação no contexto organizacional da empresa e da escola. Revista Portuguesa de Educação, Braga, v. 5, n. 3, p. 81-103, 1992.

AHRNE, G. Social organizations. Interaction Inside, Outside and Between Organizations. London: SAGE, 1997.

ARREDONDO, S. C. Vocabulario de evaluación educativa. Madrid: Pearson Educación, 2003.

BACHARACH, S. B.; LAWLER, E. J. Power and politics in organizations. San Francisco: Jossey-Bass, 1980.

BACHARACH, S. B. Notes on a political theory of educational organizations. In: WESTOBY, A. (Ed.). Culture and power in educational organizations. Philadelphia: Open University Press, 1988. p. 277-288.

BALDRIDGE, J. V. Power and conflict in the university. New York: John Wiley \& Sons, 1971.

BALDRIDGE, J. V.; CURTIS, D. V., ECKER, G.; RILEY, G. L. Policy making and effective leadership. San Francisco: Jossey-Bass, 1978.

BECHER, T. Principles and Politics: an Interpretative Framework for University Management. In: WESTOBY, A. (Ed.). Culture and power in educational organizations. Philadelphia: Open University Press, 1988. p. 317-327. 
BIRNBAUN, R. How colleges work: the cybernetics of academic organization and leadership. San Francisco: Jossey-Bass, 1988.

BOLMAN, L. G.; DEAL, T. E. Modern approaches to understanding and managing organizations. San Francisco: Jossey-Bass, 1989.

BROADFOOT, P. (Ed.). Selection, certification and control: social issues in educational assessment. London: The Falmer Press, 1984.

BUSH, T. Theories of educational administration. London: Harper \& Row, 1986.

CASTRO-ALMEIDA, C.; LE BOTERF, G.; NÓVOA, A. A avaliação participativa no decurso de projectos: reflexões a partir de uma experiência de terreno (Programa JADE). In: ESTRELA, A.; NÓVOA, A. (Orgs.). Avaliações em educação: novas perspectivas. Porto: Porto Editora, 1993. p.115-137.

COHEN, M.; MARCH, J. G. Leadership and ambiguity. New York: McGraw-Hill, 1974.

CROZIER, M. ; FRIEDBERG, E. l'acteur et le system. Les contraintes de l'action collective. Paris: Éditions du Seuil, 1977.

CROZIER, M. Le phenomene bureaucratique. Paris: Éditions du Seuil, 1963.

DAY, C. Desenvolvimento profissional de professores. Os desafios da aprendizagem permanente. Porto: Porto Editora, 2001.

DECRETO no 90/09, de 15 de Dezembro. Diário da República, I Série, n. ${ }^{\circ} 237$ - aprova as Normas Gerais Reguladoras do Subsistema de Ensino Superior., 2009

DIAS SOBRINHO, J. Avaliação da educação superior. Petrópolis: Vozes, 2000.

DIAS SOBRINHO, J. Avaliação da educação superior, regulação e emancipação. In: DIAS SOBRINHO, J.; RISTOFF, D. I. (Orgs.). Avaliação e compromisso público: a educação superior em debate. Florianópolis: Insular, 2003. p. 35-52. 
DIAS SOBRINHO, J. Universidade: Processos de socialização e processos pedagógicos. In DIAS SOBRINHO, J.; BALZAN, N. C. (Orgs.). Avaliação institucional. Teoria e Experiências. São Paulo: Cortez, 2008. p. 15-36.

DÍAZ BARRIGA, A. A Avaliação no Marco das políticas da educação superior: desafios e perspectivas. In: DIAS SOBRINHO, J. ; RISTOFF, D. I. (Orgs.). Avaliação e compromisso público: a educação superior em debate. Florianópolis: Insular, 2003. p. 77-95.

ESTÊVÃO, C. A. V. Redescobrir a escola privada portuguesa como organização. Braga: Centro de Estudos em Educação e Psicologia. Universidade do Minho, 1998.

ESTÊVÃO, C. A. V. Educação, justiça e autonomia: os lugares da escola e o bem educativo. Porto: ASA, 2004.

FACULDADE DE MEDICINA DA UNIVERSIDADE AGOSTINHO NETO - FMUAN. Relatório de avaliação. Luanda, 2006.

FERREIRA, J.; NEVES, J.; CAETANO, A. (Orgs.). Manual de psicossociologia das organizações. Lisboa: McGraw-Hill, 2001.

FRIEDBERG, E. O poder e a regra. Dinâmicas da acção organizada. Lisboa: Instituto Piaget, 1995.

FUNDAÇÃO CALOUSTE GULBENKIAN. Universidade Agostinho Neto: estudo global. Lisboa: Fundação Calouste Gulbenkian, 1987.

FUNDAÇÃO GOMES TEIXEIRA. Contributos para a revitalização da Universidade em Angola. Porto: Publicações da Universidade do Porto, 1996.

HOFSTEDE, G. Culturas e organizações: compreender a nossa programação mental. Lisboa: Sílabo, 2003.

HOUSE, E. Evaluación, ética y poder. Madrid: Morata, 2000.

LAFOND, M. A. A avaliação dos estabelecimentos de Ensino: novas práticas, novos desafios para as escolas e para a administração. In: LAFOND, M. A.; MARTÍN, E.; MARIEAU, G.; SKOVSGAARD, J.; FORMOSINHO, J.; MACHADO, J. Autonomia, gestão e avaliação das escolas. Porto: ASA, 1999. p. 9-24. 
LEITE, D. Reformas universitárias: avaliação institucional participativa. Petrópoles: Vozes, 2005.

LIMA, L. C. A Escola como organização e a participação na organização escolar. Braga: Instituto de Educação/ Universidade do Minho, 1992.

LIMA, L. C. avaliação e concepções organizacionais de escola: para uma hermenêutica organizacional. In: COSTA, J. A.; MENDES, A. N.; VENTURA, A. (Orgs.). Avaliação de organizações educativas. Aveiro: Universidade de Aveiro, 2002. p. 17-29.

LIMA, L. C. A escola como categoria na pesquisa em educação. Revista Educação Unisinos. v. 12, n. 2, p. 82-88, maio/ago, 2008. Disponível em $<$ www.unisinos.br/publicacoes_cientificas/...educacao $>$. Visitado em: 26 ago. 2008.

LUTZ, F. Tightening up Loose coupling in organizations of higher education. Administrative Science Quarterly, London, n. 27, p. 153-168, 1982.

MARCH, J. G. Analytical skills and the university training of educational administrators. In: BUSH, T. et al. (Eds.). Approaches to school management. London: Harper \& Row Publishers, 1980. p. 437-472.

MARCH, J. G. Décisions et organisations. Paris: Les Éditions d’Organisation, 1991.

MERTON, R. K. Sociologia: teoria e estrutura. São Paulo: Mestre Jou, 1970. MERTON, R. K. Estrutura burocrática e personalidade. In: CAMPOS, E. (Org.). Sociologia da burocracia. Rio de Janeiro: Zahar, 1978. p. 107-124.

MEYER, J.; ROWAN, B. Institutionalized organizations: formal structure as mith and ceremony. American Journal of Sociology, New York, n. 83, n. 2, p. 340-363, 1977.

MEYER, J., ROWAN, B. The structure of educational organizations. In: MEYER, J.; SCOTT, W. R. (Eds.). Organizational environments. Ritual and rationality. Newbury Park: SAGE, 1992.

MILLETT, J. D. New structures of campus power. San Francisco: JosseyBass, 1978. 
MINTZBERG, H. Structure et dynamique des organisations. Paris: Les Éditions d'Organisation, 1982.

MORGAN, G. Images of organization. Thousand Oaks: SAGE, 1986.

MORTIMER, K. P. ; McCONNELL, T. R. Sharing authority effectively. San Francisco: Jossey-Bass, 1978.

PINTO, M. Um olhar sobre a universidade na perspectiva do desenvolvimento social. Revista Educação e Sociedade. Colóquio educação e sociedade: reinventar a universidade, Lisboa, n. 2, p. 40-50, 1998.

POWELL, W.; DIMAGGIO, P. (Eds.). The new institutionalism in organizational analysis. Chicago: The University of Chicago Press, 1991.

PUGH, D. S.; HICKSON, D. J.; HININGS, C. R. Writers on organizations. London: Penguin Books, 1971.

RISTOFF, D. I. Algumas definições de avaliação. In: DIAS SOBRINHO, J.; RISTOFF, D. I. (Orgs.). Avaliação e compromisso público: a educação superior em debate. Florianópolis: Insular, 2003. p. 21-31.

RODRIGUES, P. A avaliação curricular. In: ESTRELA, A.; NÓVOA, A. (Orgs.). Avaliações em educação: novas perspectivas. Porto: Porto Editora, 1999. p. 15-76.

ROCHA, A. P. da. Avaliação de escolas. Porto: ASA, 1999.

SANTOS, B. S. Pela mão de Alice: o social e o político na pósmodernidade. Porto: Afrontamento, 1997.

SANTOS, B. S. A universidade no século XXI: para uma reforma democrática e emancipatória da universidade. In: SANTOS, B. de S.; ALMEIDA FILHO, N. A universidade no século XXI: para uma universidade nova. Coimbra: Almedina, 2008. p. 15-40.

SANTOS GUERRA, M. A. Entre bastidores: o lado oculto da organização. Porto: ASA, 2002.

SCOTT, W. R. Institutions and organizations. Thousand Oaks: SAGE, 1995. 
SECRETARIA DE ESTADO PARA O ENSINO SUPERIOR - SEES. Linhas mestras para a melhoria da gestão do subsistema do ensino superior. Luanda, 2005.

SECRETARIA DE ESTADO PARA O ENSINO SUPERIOR - SEES. Plano de implementação das linhas mestras para a melhoria da gestão do subsistema do ensino superior. Luanda, 2006.

SGUISSARDI, V. Para avaliar propostas de avaliação do ensino superior. Revista Portuguesa de Educação, Braga, v. 9, n. 1, p. 119-138, 1996.

SMITH, R. Conceptions of the university and demands of contemporary societies. In: BRIDGES, D.; JUCEVICIENÈ, P.; JUCEVICIUS, R.; MCLAUGHLIN, T.; STANKEVICIUTÈ, J. (Ed.). Higher education and national development. Universities and societies in transition. London and New York: Routledge, 2007. p. 30-39.

TÉRENCE, G. Encyclopédie des ressources humaines. Paris: Les Editions d'Organisation/Groupe Térence, 1994.

UNIVERSIDADE AGOSTINHO NETO - UAN. Deliberação do senado universitário, n. 015/SU/2003, de 22 de abril. Aprova o diploma sobre os procedimentos de avaliação do desempenho científico dos docentes e investigadores da UAN, 2003.

UNIVERSIDADE AGOSTINHO NETO - UAN. O deliberativo 2002-2007. n. ${ }^{\circ} 01$ (Tomo II). Luanda: EDUAN, 2007.

UNIVERSIDADE AGOSTINHO NETO - UAN. Despacho n. ${ }^{\circ}$ 51/GR/ UAN/07, de 21 de Maio. Luanda, 2007.

UNIVERSIDADE AGOSTINHO NETO - UAN. Conclusões do Conselho Consultivo sobre a Avaliação Interna. Luanda, 2009.

WEBER, M. Os fundamentos da organização burocrática. In: CAMPOS, E. (Org.). Sociologia da burocracia. Rio de Janeiro: Zahar, 1978. p. 15-28.

WEBER, M. Ensaios de sociologia. Rio de Janeiro: Zahar, 1982.

WEBER, M. Legitimate Authority and Bureaucracy. In: PUGH, D. S. Organizational theory. Selected readings. London: Penguin Books, 1984. 